\title{
Examining the Effect of Medication Adherence on Risk of Subsequent Fracture Among Women with a Fragility Fracture in the U.S. Medicare Population
}

\author{
Allison Keshishian, MPH; Natalie Boytsov, PhD; Russel Burge, PhD; Kelly Krohn, MD; \\ Louise Lombard, MA; Xiang Zhang, PhD; Lin Xie, MA, MS; and Onur Baser, MS, PhD
}

\begin{abstract}
BACKGROUND: In the United States, osteoporosis affects approximately 10 million people, of whom $80 \%$ are women, and it contributes a significant clinical burden to the community. Poor adherence to osteoporosis medications adds to the overall burden of illness.

OBJECTIVE: To examine the association of osteoporosis medication adherence and the risk of a subsequent fracture among Medicare-enrolled women with a previous fragility fracture.

METHODS: This study was a retrospective observational analysis of U.S. administrative claims data among female Medicare beneficiaries who had a nontrauma closed fragility fracture between January 1, 2011, and December 31, 2011. Patients were required to have continuous medical and pharmacy enrollment 12 months pre- and postfracture date. In addition, patients were required to have an osteoporosis medication prescription for a bisphosphonate (alendronate, risedronate, pamidronate, etidronate, zoledronate, and tiludronate), calcitonin, denosumab, raloxifene, or teriparatide during the follow-up period. Adherence was calculated using cumulative medication possession ratio (MPR) from the treatment initiation date in 30-day increments. MPR was stratified into high adherence (MPR $\geq 80 \%)$, moderate adherence $(50 \% \leq M P R>80 \%)$, and low adherence (MPR $<50 \%$ ). Outcomes included first subsequent fracture after treatment initiation; patients were censored at treatment discontinuation, or end of the 12-month period posttreatment initiation. Covariates included demographics, comorbidities, osteoporosis medications, medications associated with falls, and health care utilization. Cox regression was used to model subsequent fractures with time-dependent cumulative MPR.
\end{abstract}

RESULTS: Of the 1,292,248 Medicare enrollees who had a fracture in 2011, a total of $103,852(8.0 \%)$ women aged $\geq 65$ years with a fragility fracture were identified. Overall, $27,736(26.7 \%)$ patients were treated with osteoporosis medication within 12 months of the fragility fracture (mean time to treatment initiation was $85.0 \pm 84.6$ days). Over half of the patients were highly adherent (MPR $\geq 80 \%$ ) to osteoporosis medications during the followup $(n=14,112 ; 50.9 \%)$. Almost a third of the patients had low adherence (MPR $<50 \% ; n=9,022,32.5 \%$ ), followed by patients with moderate adherence $(50 \% \leq$ MPR $>80 \% ; n=4,602,16 \cdot 6 \%)$. After adjusting for demographics and clinical characteristics, patients with low and moderate adherence to osteoporosis medications were $33 \%$ (hazard ratio [HR]=1.33; $95 \% \mathrm{Cl}=1.17-1.50, P<0.001)$ and $19 \%(\mathrm{HR}=1.19 ; 95 \% \mathrm{Cl}=1.02-1.38$, $P=0.026$ ) more likely to have a subsequent fracture, respectively, compared with patients with high adherence. Low adherence patients had a $32 \%$ and $34 \%$ increased risk for a hip/pelvis/femur fracture $(\mathrm{HR}=1.32 ; 95 \% \mathrm{Cl}=1.09$ $1.59, P=0.005)$ and a clinical vertebral fracture $(\mathrm{HR}=1.34 ; 95 \% \mathrm{Cl}=1.09$ $1.63, P=0.005)$, respectively, compared with high adherence patients.

CONCLUSIONS: Medicare-enrolled women with low and moderate adherence to osteoporosis medications had a higher risk of a subsequent fracture compared with high adherence patients. These results highlight the importance of improving osteoporosis medication adherence among women enrolled in Medicare.

J Manag Care Spec Pharm. 2017;23(11):1178-90

Copyright $\odot 2017$, Academy of Managed Care Pharmacy. All rights reserved.

\section{What is already known about this subject}

Approximately $33 \%$ of women aged $\geq 50$ years experience osteoporotic fractures

Results from previous studies have shown overall adherence to osteoporosis medications to be $26 \%-71 \%$ and that there is a systematic relationship between increased osteoporosis medication adherence and lower risk of fractures.

A previous Medicare claims analysis has shown positive correlation between low adherence to osteoporosis medication use and increased risk of nonvertebral fractures.

\section{What this study adds}

This analysis examined the possible causation between a subsequent fracture (vertebral, hip/pelvis, femur, other nonvertebral) and adherence to all osteoporosis medications among elderly women enrolled in Medicare who previously had a fracture. Compared with patients with high adherence to osteoporosis medications, patients with low adherence were 33\% more likely to have a subsequent fracture and had a 34\% increased risk for a clinical vertebral fracture, compared with high adherence patients. This analysis suggests that Medicare patients' lower adherence to osteoporosis medications is associated with increased risk for a subsequent vertebral or nonvertebral fracture within 12 months and aligns with previous research in different populations using longer follow-up periods.

W ith osteoporosis proven to be associated with mortality due to fragility fractures, ${ }^{1-3}$ several medications have been made available to treat osteoporosis and improve the physical health of patients by significantly reducing the risk of fracture. ${ }^{4}$ However, the efficacy of osteoporosis medications informed via clinical trials may not reflect real-world practice. Real-world treatment patterns and/or 


\section{Examining the Effect of Medication Adherence on Risk of Subsequent Fracture Among Women with a Fragility Fracture in the U.S. Medicare Population}

\section{FIGURE 1 Patient Selection Flow Diagram}

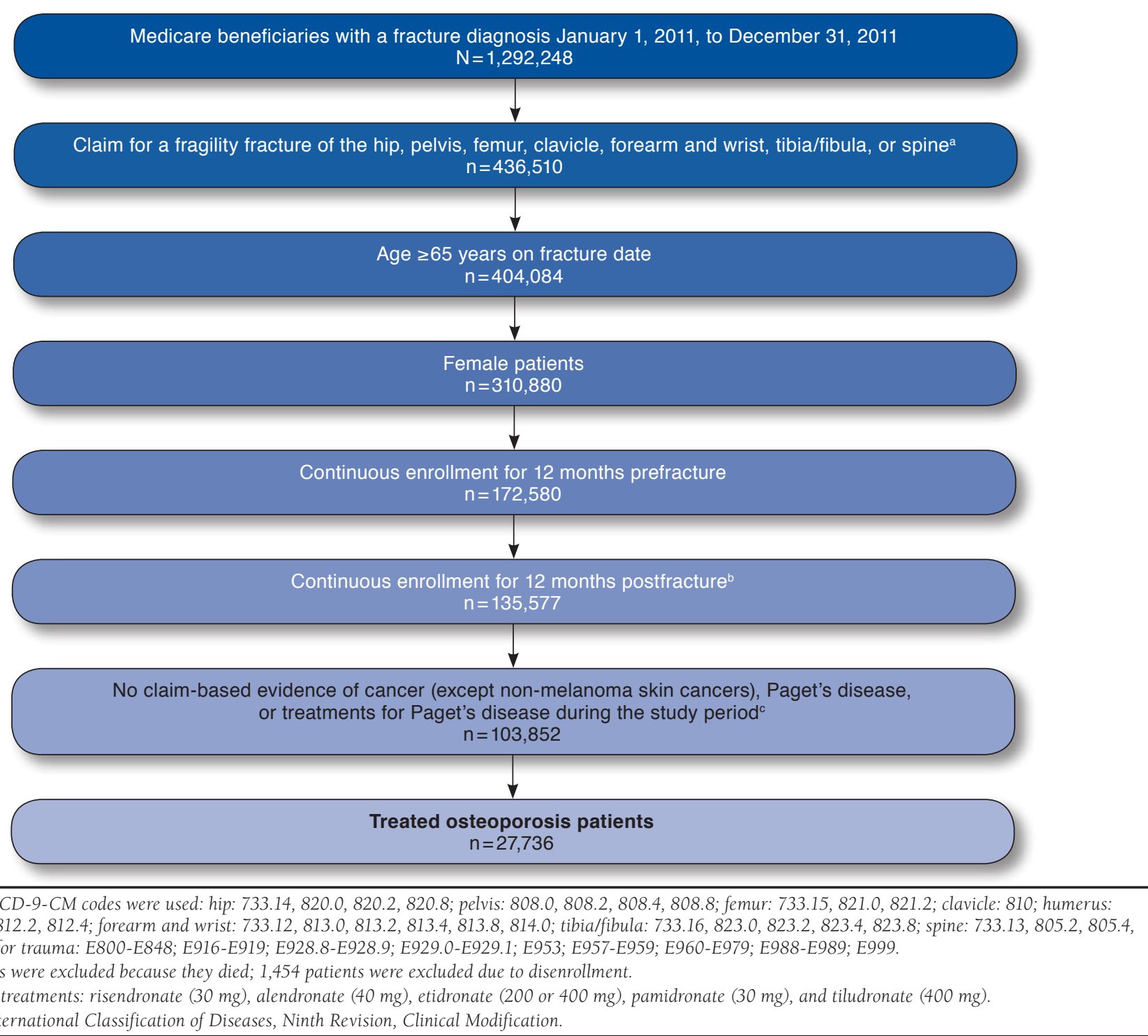

patient behaviors are different when compared with those within a controlled clinical trial environment. Medication compliance and adherence have proved to be limiting factors in predicting overall real-world effectiveness of osteoporosis medications. ${ }^{5-8}$ As such, compliance among osteoporosis patients has been relatively poor and has therefore contributed to increased fracture risk-by as much as $50 \%$ - and associated hospitalizations. ${ }^{7,9}$

Some major reasons for poor compliance include medication side effects, patients' perception of medication effectiveness, medication safety profile, and out-of-pocket medication cost. ${ }^{10}$ Other reported factors associated with low compliance include treatment administration frequency, patients' ability to follow a treatment regimen over the long term, and the health consequences of osteoporosis. ${ }^{11}$ Overall, poor medication compliance has contributed significantly to morbidity and medical costs. ${ }^{12}$ Low adherence has been shown to decrease bone mineral density (BMD), leading to more severe types of osteoporotic fracture, and higher osteoporosis-associated health care spending. ${ }^{13,14}$

To date, very few studies have explored the relationship of osteoporosis treatment adherence to subsequent fractures among Medicare enrollees. This study aims to examine the association of osteoporosis medication adherence and the risk of a subsequent fracture among Medicare-enrolled women with a previous fragility fracture. 


\section{Examining the Effect of Medication Adherence on Risk of Subsequent Fracture Among Women with a Fragility Fracture in the U.S. Medicare Population}

\section{TABLE 1 Descriptive Baseline Characteristics of Treated Patients with a Fragility Fracture}

\begin{tabular}{|c|c|c|c|c|c|c|c|c|c|c|}
\hline Baseline Characteristics & \multicolumn{2}{|c|}{ All Patients } & \multicolumn{2}{|c|}{$\begin{array}{l}\text { High Adherence } \\
\text { (MPR } \geq 80 \%)\end{array}$} & \multicolumn{3}{|c|}{$\begin{array}{l}\text { Moderate Adherence } \\
(50 \% \leq \mathrm{MPR}<80 \%)\end{array}$} & \multicolumn{3}{|c|}{$\begin{array}{l}\text { Low Adherence } \\
(\mathrm{MPR}<50 \%)\end{array}$} \\
\hline Sample Size & \multicolumn{2}{|c|}{27,736} & \multicolumn{2}{|c|}{14,112} & \multicolumn{3}{|c|}{4,602} & \multicolumn{3}{|c|}{9,022} \\
\hline & $\mathrm{n}$ & $\%$ & $\mathbf{n}$ & $\%$ & $\mathbf{n}$ & $\%$ & \begin{tabular}{|c|}
$P$ Value \\
$($ vs. High)a
\end{tabular} & $\mathbf{n}$ & $\%$ & $\begin{array}{l}P \text { Value } \\
\text { (vs. High)a }\end{array}$ \\
\hline Age (years, mean [SD]) & $81.3(7.6)$ & & $81.0(7.5)$ & & $81.8(7.8)$ & & $<0.001$ & $81.5(7.7)$ & & $<0.001$ \\
\hline \multicolumn{11}{|l|}{ Age group (years) } \\
\hline $65-74$ & 6,071 & 21.9 & 3,148 & 22.3 & 973 & 21.1 & 0.098 & 1,950 & 21.6 & 0.215 \\
\hline $75-84$ & 11,398 & 41.1 & 5,995 & 42.5 & 1,772 & 38.5 & $<0.001$ & 3,631 & 40.2 & $<0.001$ \\
\hline$\geq 85$ & 10,267 & 37.0 & 4,969 & 35.2 & 1,857 & 40.4 & $<0.001$ & 3,441 & 38.1 & $<0.001$ \\
\hline \multicolumn{11}{|l|}{ Geographic location } \\
\hline Northeast & 4,613 & 16.6 & 2,374 & 16.8 & 741 & 16.1 & 0.254 & 1,498 & 16.6 & 0.664 \\
\hline North Central & 7,953 & 28.7 & 4,320 & 30.6 & 1,251 & 27.2 & $<0.001$ & 2,382 & 26.4 & $<0.001$ \\
\hline South & 10,354 & 37.3 & 5,044 & 35.7 & 1,758 & 38.2 & 0.003 & 3,552 & 39.4 & $<0.001$ \\
\hline West & 4,791 & 17.3 & 2,363 & 16.7 & 850 & 18.5 & 0.007 & 1,578 & 17.5 & 0.141 \\
\hline Unknown & 25 & 0.1 & 11 & 0.1 & 2 & 0.0 & 0.441 & 12 & 0.1 & 0.195 \\
\hline \multicolumn{11}{|l|}{ Race } \\
\hline White & 24,965 & 90.0 & 12,771 & 90.5 & 4,062 & 88.3 & $<0.001$ & 8,132 & 90.1 & 0.363 \\
\hline Black & 615 & 2.2 & 251 & 1.8 & 128 & 2.8 & $<0.001$ & 236 & 2.6 & $<0.001$ \\
\hline Hispanic & 763 & 2.8 & 321 & 2.3 & 155 & 3.4 & $<0.001$ & 287 & 3.2 & $<0.001$ \\
\hline Other/missing & 1,393 & 5.0 & 769 & 5.4 & 257 & 5.6 & 0.726 & 367 & 4.1 & $<0.001$ \\
\hline $\begin{array}{l}\text { Medicaid dual-eligible or } \\
\text { Part D low-income subsidy }\end{array}$ & 8,386 & 30.2 & 3,992 & 28.3 & 1,619 & 35.2 & $<0.001$ & 2,775 & 30.8 & $<0.001$ \\
\hline \multicolumn{11}{|l|}{ Baseline comorbid indices } \\
\hline $\begin{array}{l}\text { Charlson Comorbidity Index } \\
\text { score (mean [SD]) }\end{array}$ & $2.5(2.1)$ & & $2.3(1.9)$ & & $2.6(2.2)$ & & $<0.001$ & $2.6(2.2)$ & & $<0.001$ \\
\hline Chronic Disease Score (mean [SD]) & $6.4(3.6)$ & & $6.3(3.6)$ & & $6.6(3.6)$ & & $<0.001$ & $6.5(3.6)$ & & $<0.001$ \\
\hline \multicolumn{11}{|l|}{ Baseline comorbid conditions } \\
\hline Congestive heart failure & 4,131 & 14.9 & 1,892 & 13.4 & 737 & 16.0 & $<0.001$ & 1,502 & 16.6 & $<0.001$ \\
\hline $\begin{array}{l}\text { Chronic obstructive pulmonary } \\
\text { disease }\end{array}$ & 7,119 & 25.7 & 3,299 & 23.4 & 1,263 & 27.0 & $<0.001$ & 2,557 & 28.3 & $<0.001$ \\
\hline Cerebrovascular disease & 1,042 & 3.8 & 491 & 3.5 & 213 & 4.6 & $<0.001$ & 338 & 3.7 & 0.286 \\
\hline Depression/bipolar disorders & 6,317 & 22.8 & 2,967 & 21.0 & 1,193 & 25.9 & $<0.001$ & 2,157 & 23.9 & $<0.001$ \\
\hline Diabetes mellitus & 6,268 & 22.6 & 3,032 & 21.5 & 1,105 & 24.0 & $<0.001$ & 2,131 & 23.6 & 0.001 \\
\hline Kidney diseases & 2,990 & 10.8 & 1,333 & 9.4 & 557 & 12.1 & $<0.001$ & 1,100 & 12.2 & $<0.001$ \\
\hline Liver diseases & 307 & 1.1 & 144 & 1.0 & 51 & 1.1 & 0.610 & 112 & 1.2 & 0.117 \\
\hline Peripheral vascular diseases & 1,828 & 6.6 & 822 & 5.8 & 320 & 7.0 & 0.006 & 686 & 7.6 & $<0.001$ \\
\hline Rheumatoid arthritis & 1,783 & 6.4 & 965 & 6.8 & 248 & 5.4 & 0.001 & 570 & 6.3 & 0.121 \\
\hline Dementia & 4,094 & 14.8 & 1,907 & 13.5 & 843 & 18.3 & $<0.001$ & 1,344 & 14.9 & 0.003 \\
\hline Thyroid-related disease & 1,412 & 5.1 & 675 & 4.8 & 227 & 4.9 & 0.681 & 510 & 5.7 & 0.003 \\
\hline Previous fracture & 19,877 & 71.7 & 9,624 & 68.2 & 3,265 & 70.9 & $<0.001$ & 6,298 & 69.8 & 0.009 \\
\hline \multicolumn{11}{|l|}{ Physician specialty } \\
\hline Rheumatology & 2,910 & 10.5 & 1,726 & 12.2 & 374 & 8.1 & $<0.001$ & 810 & 9.0 & $<0.001$ \\
\hline Endocrinology & 1,573 & 5.7 & 837 & 5.9 & 255 & 5.5 & 0.327 & 481 & 5.3 & 0.055 \\
\hline \multicolumn{11}{|l|}{ Baseline medication and procedures } \\
\hline Any osteoporosis medication & 18,286 & 65.9 & 10,003 & 70.9 & 3,327 & 72.3 & 0.066 & 4,956 & 54.9 & $<0.001$ \\
\hline Bisphosphonate & 15,265 & 55.0 & 8,423 & 59.7 & 2,745 & 59.6 & 0.963 & 4,097 & 45.4 & $<0.001$ \\
\hline Denosumab & 87 & 0.3 & 42 & 0.3 & 9 & 0.2 & 0.249 & 36 & 0.4 & 0.194 \\
\hline Calcitonin & 1,749 & 6.3 & 624 & 4.4 & 447 & 9.7 & $<0.001$ & 678 & 7.5 & $<0.001$ \\
\hline Teriparatide & 311 & 1.1 & 151 & 1.1 & 68 & 1.5 & 0.026 & 92 & 1.0 & 0.714 \\
\hline Raloxifene & 1,841 & 6.6 & 1,356 & 9.6 & 216 & 4.7 & $<0.001$ & 269 & 3.0 & $<0.001$ \\
\hline Tamoxifen & 20 & 0.1 & 12 & 0.1 & 1 & 0.0 & 0.157 & 7 & 0.1 & 0.847 \\
\hline Glucocorticoids & 13,339 & 48.1 & 6,764 & 47.9 & 2,147 & 46.7 & 0.132 & 4,428 & 49.1 & 0.088 \\
\hline Anticonvulsants & 3,111 & 11.2 & 1,542 & 10.9 & 540 & 11.7 & 0.131 & 1,029 & 11.4 & 0.259 \\
\hline Antipsychotics & 1,640 & 5.9 & 771 & 5.5 & 331 & 7.2 & $<0.001$ & 538 & 6.0 & 0.109 \\
\hline
\end{tabular}




\section{Examining the Effect of Medication Adherence on Risk of Subsequent Fracture Among Women with a Fragility Fracture in the U.S. Medicare Population}

TABLE 1 Descriptive Baseline Characteristics of Treated Patients with a Fragility Fracture (continued)

\begin{tabular}{|c|c|c|c|c|c|c|c|c|c|c|}
\hline \multirow{3}{*}{$\begin{array}{l}\text { Baseline Characteristics } \\
\text { Sample Size }\end{array}$} & \multicolumn{2}{|c|}{ All Patients } & \multicolumn{2}{|c|}{$\begin{array}{l}\text { High Adherence } \\
\text { (MPR } \geq 80 \%)\end{array}$} & \multicolumn{3}{|c|}{$\begin{array}{c}\text { Moderate Adherence } \\
(50 \% \leq \mathrm{MPR}<80 \%)\end{array}$} & \multicolumn{3}{|c|}{$\begin{array}{l}\text { Low Adherence } \\
(\mathrm{MPR}<50 \%)\end{array}$} \\
\hline & \multicolumn{2}{|c|}{27,736} & \multicolumn{2}{|c|}{14,112} & \multicolumn{3}{|c|}{4,602} & \multicolumn{3}{|c|}{9,022} \\
\hline & $\mathbf{n}$ & $\%$ & $\mathbf{n}$ & $\%$ & $\mathbf{n}$ & $\%$ & $\begin{array}{c}P \text { Value } \\
\text { (vs. High)a }\end{array}$ & $\mathbf{n}$ & $\%$ & $\begin{array}{c}P \text { Value } \\
\text { (vs. High)a }^{\text {a }}\end{array}$ \\
\hline \multicolumn{11}{|l|}{ Baseline medication and procedures } \\
\hline Tricyclic antidepressants & 1,600 & 5.8 & 785 & 5.6 & 270 & 5.9 & 0.437 & 545 & 6.0 & 0.128 \\
\hline SSRIs & 8,138 & 29.3 & 3,915 & 27.7 & 1,514 & 32.9 & $<0.001$ & 2,709 & 30.0 & $<0.001$ \\
\hline Benzodiazepines & 3,198 & 11.5 & 1,664 & 11.8 & 497 & 10.8 & 0.068 & 1,037 & 11.5 & 0.492 \\
\hline Nonbenzodiazepines hypnotics & 2,937 & 10.6 & 1,426 & 10.1 & 513 & 11.2 & 0.044 & 998 & 11.1 & 0.020 \\
\hline BMD test & 5,839 & 21.1 & 3,289 & 23.3 & 896 & 19.5 & $<0.001$ & 1,654 & 18.3 & $<0.001$ \\
\hline \multicolumn{11}{|c|}{ Baseline all-cause health care utilization } \\
\hline Any inpatient stay & 20,195 & 72.8 & 10,072 & 71.4 & 3,431 & 74.6 & $<0.001$ & 6,692 & 74.2 & $<0.001$ \\
\hline Any ER visit & 12,074 & 43.5 & 5,886 & 41.7 & 2,031 & 44.1 & 0.004 & 4,157 & 46.1 & $<0.001$ \\
\hline Any outpatient visit & 24,191 & 87.2 & 12,302 & 87.2 & 4,079 & 88.6 & 0.009 & 7,810 & 86.6 & 0.181 \\
\hline $\begin{array}{l}\text { Any Part D prescriptions } \\
\text { pharmacy visit }\end{array}$ & 27,541 & 99.3 & 14,011 & 99.3 & 4,578 & 99.5 & 0.160 & 8,952 & 99.2 & 0.602 \\
\hline Any DME visit & 12,429 & 44.8 & 6,138 & 43.5 & 2,113 & 45.9 & 0.004 & 4,178 & 46.3 & $<0.001$ \\
\hline Any SNF visit & 3,673 & 13.2 & 1,683 & 11.9 & 739 & 16.1 & $<0.001$ & 1,251 & 13.9 & $<0.001$ \\
\hline Any HHA visit & 6,667 & 24.0 & 3,106 & 22.0 & 1,203 & 26.1 & $<0.001$ & 2,358 & 26.1 & $<0.001$ \\
\hline Any hospice visit & 125 & 0.5 & 44 & 0.3 & 25 & 0.5 & 0.024 & 56 & 0.6 & $<0.001$ \\
\hline
\end{tabular}

aBold $P$ values indicate significance at $P<0.05$

$B M D=$ bone mineral density; $D M E=$ durable medical equipment; $E R=$ emergency room; HHA=home health agency; $S D=$ standard deviation; $S N F=$ skilled nursing facility; SSRI = selective serotonin reuptake inhibitor.

\section{Methods}

\section{Data Source}

This study was a retrospective observational analysis of U.S. administrative claims data of female fee-for-service (FFS) Medicare beneficiaries from January 1, 2010, through December 31, 2012, with identification of patients with a fragility fracture between January 1, 2011, and December 31, 2011. The Medicare database captures comprehensive demographic and clinical information. Study variables were measured from the database using enrollment records, International Classification of Diseases, 9th Revision, Clinical Modification (ICD-9-CM) codes, Healthcare Common Procedure Coding System codes, and National Drug Code numbers, as appropriate.

This observational study was conducted under the provisions of Privacy Rule 45 CFR 164.514(e) and was exempt from investigational review board review and approval, as there was no collection or use of personally identifiable information in the conduct of this study. ${ }^{15}$

\section{Study Population}

Patients were included in the study if they had (a) an inpatient hospital stay with a primary discharge diagnosis of fragility fracture (closed fracture without trauma codes), defined as a fragility fracture of the hip, pelvis, femur, clavicle, humerus, forearm and wrist, tibia/fibula, or spine, or (b) had at least 2 medical claims for clavicle, humerus, forearm and wrist, tibia/fibula, or spine fractures in an outpatient setting $\geq 90$ days apart for the same fracture site between January 1, 2011, and December 31, 2011 (cohort entry). ${ }^{16,17}$ Fractures with a trauma code identified within 7 days before or after the fracture claim date were excluded. Further, patients were included if they were women aged $\geq 65$ years on the fragility fracture date and had continuous FFS Medicare enrollment in Part A (hospitalization), Part B (outpatient medical care), and Part D (prescription drugs) for 12 months before and after the fragility fracture date. Patients were excluded from the study if they had claim-based evidence of cancer, Paget's disease, or treatments for Paget's disease during the study period (Figure 1) or if they died during the 1-year follow-up period.

Patients were required to have an osteoporosis medication prescription, defined as a record of a claim for a bisphosphonate (alendronate, risedronate, pamidronate, etidronate, zoledronate, and tiludronate); calcitonin; denosumab; raloxifene; or teriparatide during the follow-up period. Patients were then evaluated for subsequent fractures after treatment initiation until either treatment discontinuation, first subsequent fracture during the treatment, or the end of the 12-month followup period (after the treatment initiation), whichever came first. Discontinuation of treatment was defined as no evidence of any osteoporosis-related prescription at any time after the last date of the previous fill during the study follow-up. 


\section{Study Variables}

Baseline demographic and clinical characteristics during the 12 months before the initial fragility fracture were measured among all treated osteoporosis patients. Baseline characteristics included demographics (gender, age, race, U.S. geographic region, and Medicaid dual-eligible or low-income subsidy); comorbidities (congestive heart failure, chronic obstructive pulmonary disease [COPD], cerebrovascular disease, depression, diabetes, kidney disease, liver disease, peripheral vascular disease, rheumatoid arthritis, dementia, thyroid disease, and baseline fracture); Charlson Comorbidity Index (CCI) score $^{18}$; Chronic Disease Score ${ }^{19}$; medication use (osteoporosis medications, glucocorticoids, tricyclic antidepressants [TCAs], selective serotonin reuptake inhibitors [SSRIs], benzodiazepines, nonbenzodiazepine hypnotics, and anticonvulsant drugs ${ }^{20}$; previous fracture (previous fragility fracture in baseline); physician specialty (rheumatology and endocrinology visits); and health care utilization. Health care utilization included inpatient, office, and emergency room (ER) visits, pharmacy claims, use of durable medical equipment, and home health agency, hospice, and skilled nursing facility claims.

Adherence to osteoporosis treatments was measured by a medication possession ratio (MPR) using osteoporosis medication pharmacy claims. Overall MPR was calculated by dividing the cumulative days supply of the osteoporosis medications by the number of days of follow-up. The cumulative days supply was defined as the number of days during the follow-up period when the patient was in possession of the osteoporosis medication. Cumulative MPR was calculated from the treatment prescription date in 30-day increments and plotted against time (in months) for descriptive analysis. For each month, the numerator consisted of days supply of an osteoporosis prescription fill for the current month, plus the previous month(s), divided by the length of follow-up for that patient. ${ }^{13,21}$ Continuous MPR values were converted into categorical variables: high adherence MPR $\geq 80 \%, 22$ moderate adherence $50 \% \leq \mathrm{MPR}>80 \%$, and low adherence $\mathrm{MPR}<50 \% .{ }^{23}$ Time-dependent cumulative MPR was included as a primary predictor of subsequent fracture in the multivariate analysis.

Subsequent fracture events, which occurred after treatment initiation and before treatment discontinuation, were defined using the same criteria as initial fragility fractures. Fractures due to trauma were excluded, since those are not likely due to osteoporosis. Patient data were evaluated overall and stratified into 3 subgroups per subsequent fracture site: hip, pelvis, femur regions denoted as "hip/pelvis/femur fractures"; fractures in the vertebral regions denoted as "clinical vertebral fractures"; and fractures in the nonvertebral regions of clavicle, humerus, forearm and wrist, or tibia/fibula denoted as "other nonvertebral fractures."

\section{Statistical Analysis}

Baseline and outcome variables were analyzed descriptively. Counts, percentages, means, and standard deviations were provided for appropriate variables. T-tests and chi-square tests were used for continuous and categorical variables, respectively.

The cumulative incidence of subsequent fractures was analyzed descriptively and stratified by MPR categories. In addition, cumulative MPR was analyzed each month after the osteoporosis medication prescription to evaluate adherence levels across the follow-up period.

Cox proportional hazards models were used to evaluate the causal relationship between time-dependent cumulative adherence and the first subsequent fracture after the osteoporosis medication prescription..$^{21,24}$ The dependent variable was time to subsequent fracture, and the independent variables included demographics, comorbidities, baseline fracture, baseline medications, baseline BMD test (yes/no), health care utilization, and time-dependent cumulative adherence. For each patient, adherence levels were calculated in 30-day intervals, and appropriate cumulative adherence (up to the last 30-day increment before the first subsequent fracture) was applied to the first subsequent fracture in the multivariate analysis. Cox models were also used to evaluate subsequent fractures stratified by hip/pelvis/femur, clinical vertebral, and other nonvertebral fractures.

A sensitivity analysis was completed among patients with a baseline osteoporosis medication to examine the risk of fracture by controlling for pre-index osteoporosis medication MPR in the baseline period.

The healthy adherer effect is a commonly identified bias in observational studies, in which high adherence patients may differ in many ways compared with low adherence patients; therefore, there may be residual confounding due to unmeasured factors. While examining the effect of 1 preventive service (e.g., osteoporosis treatment) on fracture risk, the inability to adjust for all other related preventive behaviors could overestimate their effect.

Claims databases, such as Medicare, are unable to measure and control for all possible healthy-status and healthy-lifestyle behaviors. Therefore, we conducted diagnostic tests, in which several control outcomes (unrelated to osteoporosis) were tested for their association with time-dependent osteoporosis medication adherence..$^{25,26}$ Differences across these unrelated "falsification" outcomes between adherence cohorts would reflect unmeasured differences in healthy behaviors in the sample. These falsification outcomes included inpatient admissions of pneumonia, organism unspecified (ICD-9-CM code 486), unspecified septicemia (ICD-9-CM code 038.9), chronic obstructive bronchitis with acute exacerbation (ICD-9-CM code 491.21), urinary tract infection site not specified (ICD9-CM code 599.0), atrial fibrillation (ICD-9-CM code 427.31), and coronary atherosclerosis of native coronary artery (ICD- 


\section{Examining the Effect of Medication Adherence on Risk of Subsequent Fracture Among Women with a Fragility Fracture in the U.S. Medicare Population}

TABLE 2 Descriptive Outcomes Stratified by Medication Adherence

\begin{tabular}{|c|c|c|c|c|c|c|c|c|c|c|}
\hline & \multicolumn{2}{|c|}{$\begin{array}{l}\text { All Patients } \\
(\mathrm{N}=27,736)\end{array}$} & \multicolumn{2}{|c|}{$\begin{array}{l}\text { High Adherence } \\
(\mathrm{MPR} \geq 80 \%) \\
(\mathrm{n}=14,112)\end{array}$} & \multicolumn{3}{|c|}{$\begin{array}{c}\text { Moderate Adherence } \\
(50 \% \leq \mathrm{MPR}<80 \%) \\
(\mathrm{n}=4,602)\end{array}$} & \multicolumn{3}{|c|}{$\begin{array}{l}\text { Low Adherence } \\
\quad(\mathrm{MPR}<50 \%) \\
(\mathrm{n}=9,022)\end{array}$} \\
\hline & $\mathrm{n}$ & $\%$ & $\mathrm{n}$ & $\%$ & n & $\%$ & $P$ Value ${ }^{a}$ & n & $\%$ & $P$ Value $^{\mathrm{a}}$ \\
\hline All fractures & 1,765 & 6.4 & 677 & 4.8 & 402 & 8.7 & $<0.001$ & 686 & 7.6 & $<0.001$ \\
\hline Hip/pelvis/femur fractures & 909 & 51.5 & 311 & 45.9 & 214 & 53.2 & $<0.001$ & 384 & 56.0 & $<0.001$ \\
\hline Clinical vertebral fractures & 455 & 25.8 & 195 & 28.8 & 98 & 24.4 & $<0.001$ & 162 & 23.6 & $<0.013$ \\
\hline Other nonvertebral fractures & 410 & 23.2 & 174 & 25.7 & 93 & 23.1 & $<0.001$ & 143 & 20.9 & 0.025 \\
\hline $\begin{array}{l}\text { Time from index fracture to } \\
\text { osteoporosis medication } \\
\text { prescription (mean [SD]) }\end{array}$ & 85.0 & {$[84.6]$} & 87.1 & [86.1] & 73.0 & {$[72.8]$} & $<0.001$ & 87.9 & [87.4] & 0.493 \\
\hline $\begin{array}{l}\text { Time from index fracture to } \\
\text { osteoporosis medication } \\
\text { prescription (median days) }\end{array}$ & 57.0 & & 59.0 & & 51.0 & & & 58.0 & & \\
\hline
\end{tabular}

aBold $P$ values indicate significance at $P<0.05$. $P$ values were calculated using the high $M P R$ cohort $(M P R \geq 80 \%)$ as the reference.

$M P R=$ medication possession ratio; $S D=$ standard deviation .

9-CM code 414.01). ${ }^{24}$ For the falsification analysis, the same statistical methods as the primary analysis were used.

For each variable, the hazard ratio (HR), 95\% confidence interval (CI), and $P$ value were reported. All analyses were carried out using SAS software package 9.3 (SAS Institute, Cary, NC). $P$ values $<0.050$ were considered statistically significant.

\section{Results}

Of the 1,292,248 Medicare enrollees who had a fracture in 2011 , a total of 103,852 (8.0\%) women $\geq 65$ years of age with a fragility fracture were identified. Overall, 27,736 (26.7\%) patients were treated with osteoporosis medication within 12 months of the fragility fracture (Figure 1). During the baseline period, $66 \%$ of patients had an osteoporosis medication prescription.

The mean time to osteoporosis prescription from fragility fracture date was $85.0 \pm 84.6$ days. Over half of the patients were highly adherent $(\mathrm{MPR} \geq 80 \%)$ to their osteoporosis medication $(n=14,112,50.9 \%)$. Approximately one third of the patients had low adherence (MPR $<50 \%$; $n=9,022,32.5 \%$ ), followed by patients with moderate adherence $(50 \% \leq \mathrm{MPR}>80 \%$; $\mathrm{n}=4,602,16.6 \%)$. The median time to treatment initiation was 58,51 , and 59 days for the low, moderate, and high adherence patients, respectively.

Baseline characteristics for patients are shown in Table 1. Patients had an average age of $81.3 \pm 7.6$ years with a mean CCI score of $2.5 \pm 2.1$. The most common comorbid conditions included COPD (25.7\%), diabetes mellitus (22.6\%), depression/ bipolar disorders (22.8\%), and dementia (14.8\%). Also, about half of the sample was prescribed glucocorticoids (48.1\%) and bisphosphonates (55.0\%) during the baseline period. Less than one quarter of patients had a BMD test during the baseline period (21.1\%).
Patients with low and moderate adherence were older compared with patients with high adherence. In addition, during the baseline period, a greater proportion of moderate and low adherence patients were shown to have significantly greater clinical comorbidities, including congestive heart failure, COPD, depression/bipolar disorders, and dementia, compared with high adherence patients $(P<0.001)$. Moderate and low adherence patients had significantly lower rates of BMD tests compared with high adherence patients (19.5\% and $18.3 \%$ vs. $23.3 \%$, respectively, $P<0.001$ ). A greater proportion of low adherence patients were prescribed glucocorticoids compared with high adherence patients (49.1\% vs. $47.9 \%, P=0.088$ ), while fewer low adherence patients were prescribed bisphosphonates compared with high adherence patients (45.4\% vs. $59.7 \%, P<0.001)$. Low adherence patients were more likely to be prescribed SSRIs compared with high adherence patients (30.0\% vs. $27.7 \%, P<0.001$ ).

The number of fractures by fracture type and stratified by MPR are shown in Table 2. Overall, 6.4\% of treated patients had a subsequent fracture during the follow-up period while on therapy. Patients with high adherence had the lowest proportion of fractures (4.8\%). Hip/pelvis/femur fractures were the most common type of fracture across all adherence levels, followed by clinical vertebral fractures and other nonvertebral fractures. Low $(56.0 \%, P<0.001)$ and moderate adherence $(53.2 \%$, $P<0.001)$ patients had a higher proportion of hip/pelvis/femur fractures compared with high adherence patients (45.9\%).

Figure 2 shows the cumulative incidence of subsequent fracture by MPR. Overall, high adherence patients had a lower cumulative incidence of a subsequent fracture compared with moderate and low adherence patients.

The cumulative MPR after treatment initiation suggested that there was a gradual decline over the 12 months after treat- 


\section{FIGURE 2 Cumulative Incidence of Subsequent Fracture Stratified by Medication Possession Ratio}

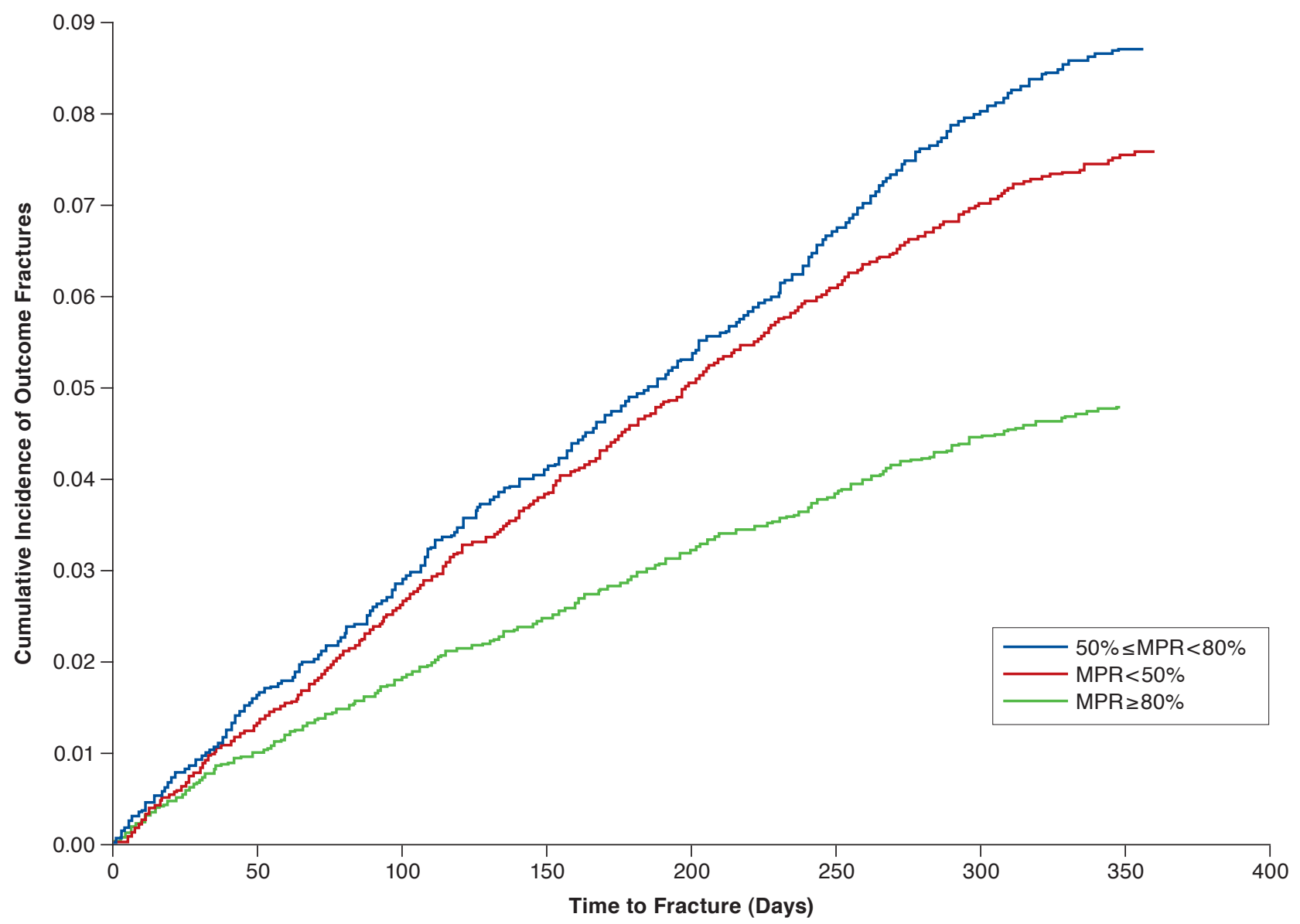

MPR=medication possession ratio.

ment initiation: the MPR at 3, 6, 9, and 12 months was 83\%, $76 \%, 71 \%$, and $68 \%$, respectively.

\section{Effect of Adherence on Risk of Subsequent Fracture}

The multivariable Cox proportional hazards models for predictors of subsequent fracture are shown in Table 3.

Patients with low adherence were 33\% more likely to have a subsequent fracture $(\mathrm{HR}=1.33 ; 95 \% \mathrm{CI}=1.17-1.50, \mathrm{P}<0.001)$ compared with patients with high adherence to osteoporosis medications. Moderate adherence patients had a 19\% higher risk of a subsequent fracture ( $\mathrm{HR}=1.19 ; 95 \% \mathrm{CI}=1.02-1.38$, $P=0.026)$ compared with high adherence patients. When the subsequent fractures were stratified by fracture type, the results were generally consistent with overall findings on fractures. Low adherence patients had a $32 \%$ and 34\% increased risk for a hip/pelvis/femur fracture $(\mathrm{HR}=1.32 ; 95 \% \mathrm{CI}=1.09-1.59$, $P=0.005)$ and a clinical vertebral fracture $(\mathrm{HR}=1.34 ; 95 \% \mathrm{CI}=$ 1.09-1.63, $P=0.005)$, respectively, compared with high adher- ence patients. The effect of MPR level on other nonvertebral fractures was not statistically significant in our analysis.

Other baseline covariates that significantly increased the risk of a subsequent fracture included older age ( $\geq 85$ years: $H R=1.61$; 95\% CI $=1.40-1.86, \quad P<0.001 ; 75-84$ years: $\mathrm{HR}=1.36 ; 95 \%$ $\mathrm{CI}=1.18-1.56, P<0.001)$; higher $\mathrm{CCI}$ score $(\mathrm{HR}=1.09 ; 95 \% \mathrm{CI}=$ 1.05-1.13, $P<0.001)$; thyroid-related disease $(\mathrm{HR}=1.23 ; 95 \% \mathrm{CI}=$ 1.01-1.48; $P=0.039)$; and baseline TCA use $(H R=1.26 ; 95 \%$ $\mathrm{CI}=1.05-1.51, P=0.013)$. However, black race $(\mathrm{HR}=0.58 ; 95 \%$ $\mathrm{CI}=0.39-0.88, P=0.009$ ); kidney diseases $(\mathrm{HR}=0.84 ; 95 \% \mathrm{CI}=$ 0.71-0.99, $P=0.037$ ); and BMD tests ( $\mathrm{HR}=0.86$; $95 \% \mathrm{CI}=0.76$ $0.98, P=0.019)$ were associated with lower likelihood of a subsequent fracture.

Results of the sensitivity analysis were generally consistent with those for the main analysis. When baseline osteoporosis medication MPR was controlled, low adherence patients had a $27 \%$ increased risk of fracture $(\mathrm{HR}=1.27 ; 95 \% \mathrm{CI}=1.08-1.49$, 


\section{Examining the Effect of Medication Adherence on Risk of Subsequent Fracture Among Women with a Fragility Fracture in the U.S. Medicare Population}

\section{TABLE 3 Cox Proportional Hazards Models for Subsequent Fractures with Time-Dependent Adherence}

\begin{tabular}{|c|c|c|c|c|c|c|}
\hline \multirow[b]{2}{*}{ Covariates } & \multicolumn{3}{|c|}{ Any Fracture } & \multicolumn{3}{|c|}{ Hip/Pelvis/Femur Fracture } \\
\hline & Hazard Ratio & $95 \% \mathrm{CI}$ & $P$ Value ${ }^{a}$ & Hazard Ratio & $95 \% \mathrm{CI}$ & $P$ Value \\
\hline \multicolumn{7}{|l|}{ Adherence } \\
\hline \multicolumn{7}{|l|}{ High $($ MPR $>80 \%)$ (reference) } \\
\hline Moderate $(50 \% \leq$ MPR $<80 \%)$ & 1.19 & $1.02-1.38$ & 0.026 & 1.11 & $0.88-1.39$ & 0.372 \\
\hline Low (MPR < $50 \%)$ & 1.33 & $1.17-1.50$ & $<0.001$ & 1.32 & $1.09-1.59$ & 0.005 \\
\hline \multicolumn{7}{|l|}{ Age group (years) } \\
\hline \multicolumn{7}{|l|}{ 65-74 (reference) } \\
\hline $75-84$ & 1.36 & $1.18-1.56$ & $<0.001$ & 1.19 & $0.95-1.49$ & 0.126 \\
\hline$\geq 85$ & 1.61 & $1.40-1.86$ & $<0.001$ & 1.46 & $1.17-1.82$ & 0.001 \\
\hline \multicolumn{7}{|l|}{ U.S. geographic region } \\
\hline \multicolumn{7}{|l|}{ Northeast (reference) } \\
\hline North Central & 1.07 & $0.93-1.23$ & 0.341 & 1.03 & $0.83-1.29$ & 0.771 \\
\hline South & 0.96 & $0.84-1.11$ & 0.607 & 1.08 & $0.87-1.33$ & 0.485 \\
\hline West & 0.90 & $0.76-1.06$ & 0.197 & 0.93 & $0.72-1.19$ & 0.542 \\
\hline \multicolumn{7}{|l|}{ Race } \\
\hline \multicolumn{7}{|l|}{ White (reference) } \\
\hline Black & 0.58 & $0.39-0.88$ & 0.009 & 0.56 & $0.32-1.00$ & 0.051 \\
\hline Hispanic & 0.91 & $0.67-1.23$ & 0.540 & 0.88 & $0.56-1.38$ & 0.575 \\
\hline Other/missing & 0.96 & $0.76-1.22$ & 0.745 & 1.09 & $0.78-1.53$ & 0.601 \\
\hline \multicolumn{7}{|l|}{ Baseline comorbid conditions } \\
\hline Charlson Comorbidity Index score & 1.09 & $1.05-1.13$ & $<0.001$ & 1.08 & $1.02-1.14$ & 0.010 \\
\hline Chronic Disease Score & 1.00 & $0.98-1.01$ & 0.746 & 1.00 & $0.97-1.02$ & 0.863 \\
\hline Congestive heart failure & 0.87 & $0.75-1.01$ & 0.062 & 0.90 & $0.73-1.11$ & 0.305 \\
\hline Cerebrovascular disease & 0.80 & $0.63-1.03$ & 0.078 & 0.79 & $0.55-1.11$ & 0.175 \\
\hline Depression/bipolar disorders & 1.01 & $0.89-1.15$ & 0.877 & 0.95 & $0.79-1.15$ & 0.620 \\
\hline Diabetes mellitus & 0.91 & $0.80-1.04$ & 0.165 & 0.95 & $0.78-1.15$ & 0.584 \\
\hline Kidney diseases & 0.84 & $0.71-0.99$ & 0.037 & 0.74 & $0.58-0.95$ & 0.018 \\
\hline Liver diseases & 1.42 & $0.98-2.06$ & 0.062 & 1.55 & $0.88-2.72$ & 0.130 \\
\hline Dementia & 1.13 & $0.99-1.28$ & 0.065 & 1.15 & $0.96-1.37$ & 0.123 \\
\hline Thyroid-related disease & 1.23 & $1.01-1.48$ & 0.039 & 1.26 & $0.95-1.67$ & 0.112 \\
\hline Previous fracture & 1.04 & $0.93-1.17$ & 0.512 & 0.75 & $0.59-0.96$ & 0.020 \\
\hline \multicolumn{7}{|l|}{ Baseline medication and procedures } \\
\hline Baseline osteoporosis medication & 1.10 & $0.99-1.23$ & 0.066 & 1.18 & $1.01-1.39$ & 0.040 \\
\hline BMD test & 0.86 & $0.76-0.98$ & 0.019 & 0.86 & $0.71-1.04$ & 0.115 \\
\hline Anticonvulsant therapies & 1.06 & $0.91-1.23$ & 0.437 & 1.00 & $0.80-1.26$ & 0.988 \\
\hline Antipsychotics & 1.11 & $0.92-1.34$ & 0.263 & 1.01 & $0.78-1.32$ & 0.935 \\
\hline Tricyclic antidepressants & 1.26 & $1.05-1.51$ & 0.013 & 1.51 & $1.16-1.96$ & 0.002 \\
\hline SSRIs & 1.08 & $0.97-1.21$ & 0.171 & 1.15 & $0.96-1.36$ & 0.123 \\
\hline Benzodiazepines & 1.06 & $0.91-1.22$ & 0.469 & 0.94 & $0.74-1.20$ & 0.627 \\
\hline Nonbenzodiazepines hypnotics & 1.11 & $0.95-1.28$ & 0.182 & 1.24 & $1.00-1.53$ & 0.054 \\
\hline Medicaid dual-eligible/Part D low-income subsidy & 1.01 & $0.90-1.12$ & 0.916 & 1.04 & $0.88-1.22$ & 0.664 \\
\hline \multicolumn{7}{|l|}{ Health care utilization } \\
\hline ER visit & 1.04 & $1.01-1.07$ & 0.005 & 1.05 & $1.01-1.10$ & 0.024 \\
\hline \multirow[t]{2}{*}{ Inpatient visit } & 1.05 & $1.00-1.10$ & 0.036 & 1.12 & $1.05-1.21$ & 0.001 \\
\hline & \multicolumn{3}{|c|}{ Clinical Vertebral Fracture } & \multicolumn{3}{|c|}{ Other Nonvertebral Fracture } \\
\hline Covariates & Hazard Ratio & $95 \% \mathrm{CI}$ & $P$ Value & Hazard Ratio & $95 \%$ CI & $P$ Value \\
\hline \multicolumn{7}{|l|}{ Adherence } \\
\hline High (MPR $\geq 80 \%$ ) (reference) & & & & & & \\
\hline Moderate $(50 \% \leq \mathrm{MPR}<80 \%)$ & 1.26 & $0.98-1.61$ & 0.070 & 1.34 & $0.97-1.84$ & 0.076 \\
\hline Low $(\mathrm{MPR}<50 \%)$ & 1.34 & $1.09-1.63$ & 0.005 & 1.31 & $0.97-1.75$ & 0.075 \\
\hline Age group (years) & & & & & & \\
\hline 65-74 (reference) & & & & & & \\
\hline $75-84$ & 1.28 & $1.01-1.63$ & 0.043 & 1.61 & $1.22-2.11$ & $<0.001$ \\
\hline$\geq 85$ & 1.43 & $1.12-1.84$ & 0.004 & 2.12 & $1.58-2.84$ & $<0.001$ \\
\hline
\end{tabular}




\section{Examining the Effect of Medication Adherence on Risk of Subsequent Fracture Among Women with a Fragility Fracture in the U.S. Medicare Population}

TABLE 3 Cox Proportional Hazards Models for Subsequent Fractures with Time-Dependent Adherence (continued)

\begin{tabular}{|c|c|c|c|c|c|c|}
\hline \multirow{2}{*}{ Covariates } & \multicolumn{3}{|c|}{ Clinical Vertebral Fracture } & \multicolumn{3}{|c|}{ Other Nonvertebral Fracture } \\
\hline & Hazard Ratio & $95 \%$ CI & $P$ Value ${ }^{\mathrm{a}}$ & Hazard Ratio & $95 \% \mathrm{CI}$ & $P$ Value ${ }^{\mathrm{a}}$ \\
\hline \multicolumn{7}{|l|}{ U.S. geographic region } \\
\hline \multicolumn{7}{|l|}{ Northeast (reference) } \\
\hline North Central & 0.89 & $0.71-1.11$ & 0.296 & 1.60 & $1.16-2.19$ & 0.004 \\
\hline South & 0.77 & $0.62-0.97$ & 0.025 & 1.18 & $0.86-1.63$ & 0.300 \\
\hline West & 0.68 & $0.51-0.90$ & 0.007 & 1.42 & $0.99-2.04$ & 0.056 \\
\hline \multicolumn{7}{|l|}{ Race } \\
\hline \multicolumn{7}{|l|}{ White (reference) } \\
\hline Black & 0.80 & $0.38-1.70$ & 0.566 & 0.58 & $0.26-1.31$ & 0.188 \\
\hline Hispanic & 1.14 & $0.68-1.90$ & 0.615 & 0.69 & $0.36-1.32$ & 0.263 \\
\hline Other/missing & 0.86 & $0.56-1.32$ & 0.482 & 0.86 & $0.50-1.49$ & 0.597 \\
\hline \multicolumn{7}{|l|}{ Baseline comorbid conditions } \\
\hline Charlson Comorbidity Index score & 1.10 & $1.03-1.17$ & 0.005 & 1.08 & $1.00-1.18$ & 0.051 \\
\hline Chronic Disease Score & 0.98 & $0.96-1.01$ & 0.173 & 1.02 & $0.99-1.06$ & 0.235 \\
\hline Congestive heart failure & 0.87 & $0.68-1.11$ & 0.259 & 0.91 & $0.65-1.28$ & 0.594 \\
\hline Cerebrovascular disease & 0.77 & $0.50-1.19$ & 0.237 & 0.84 & $0.47-1.49$ & 0.545 \\
\hline Depression/bipolar disorders & 0.93 & $0.74-1.17$ & 0.534 & 1.35 & $1.02-1.79$ & 0.038 \\
\hline Diabetes mellitus & 0.91 & $0.72-1.15$ & 0.418 & 0.90 & $0.68-1.20$ & 0.479 \\
\hline Kidney diseases & 1.04 & $0.78-1.39$ & 0.778 & 0.84 & $0.56-1.25$ & 0.391 \\
\hline Liver diseases & 0.94 & $0.46-1.92$ & 0.868 & 2.40 & $1.21-4.74$ & 0.012 \\
\hline Dementia & 1.26 & $1.00-1.59$ & 0.048 & 0.93 & $0.68-1.27$ & 0.627 \\
\hline Thyroid-related disease & 1.21 & $0.88-1.67$ & 0.245 & 1.14 & $0.74-1.76$ & 0.565 \\
\hline Previous fracture & 1.15 & $0.96-1.38$ & 0.119 & 1.28 & $1.01-1.61$ & 0.039 \\
\hline \multicolumn{7}{|l|}{ Baseline medication and procedures } \\
\hline Baseline osteoporosis medication & 1.05 & $0.89-1.24$ & 0.593 & 1.13 & $0.87-1.45$ & 0.363 \\
\hline BMD test & 0.93 & $0.76-1.14$ & 0.485 & 0.76 & $0.58-0.99$ & 0.044 \\
\hline Anticonvulsant therapies & 1.04 & $0.80-1.34$ & 0.794 & 1.22 & $0.90-1.66$ & 0.201 \\
\hline Antipsychotics & 1.19 & $0.85-1.67$ & 0.316 & 1.31 & $0.90-1.91$ & 0.163 \\
\hline Tricyclic antidepressants & 0.92 & $0.65-1.30$ & 0.624 & 1.29 & $0.88-1.89$ & 0.199 \\
\hline SSRIs & 1.08 & $0.89-1.31$ & 0.440 & 1.04 & $0.82-1.32$ & 0.741 \\
\hline Benzodiazepines & 1.14 & $0.90-1.44$ & 0.272 & 1.09 & $0.80-1.48$ & 0.600 \\
\hline Nonbenzodiazepine hypnotics & 1.01 & $0.78-1.30$ & 0.962 & 1.02 & $0.74-1.40$ & 0.916 \\
\hline Medicaid dual-eligible/Part D low-income subsidy & 0.94 & $0.77-1.14$ & 0.525 & 1.01 & $0.80-1.28$ & 0.927 \\
\hline \multicolumn{7}{|l|}{ Health care utilization } \\
\hline ER visit & 1.02 & $0.97-1.07$ & 0.429 & 1.06 & $0.98-1.15$ & 0.139 \\
\hline Inpatient visit & 1.01 & $0.94-1.09$ & 0.737 & 0.96 & $0.85-1.07$ & 0.435 \\
\hline
\end{tabular}

aBold $P$ values indicate significance at $P<0.05$.

$B M D=$ bone mineral density; $C I=$ confidence interval; $E R=$ emergency room; $M P R=$ medication possession ratio; SSRI= selective serotonin reuptake inhibitor.

$P=0.004)$ compared with high adherence patients (Appendix A, available in online article).

The falsification outcomes analysis showed that none of the unrelated control outcomes were significantly associated with osteoporosis medication adherence. Therefore, this analysis suggests a lack of healthy adherer bias in our study population (Appendix B, available in online article).

\section{Discussion}

The current study was a real-world retrospective observational analysis to examine the correlates of subsequent fracture and the relative impact of medication adherence on risk of fracture in a large Medicare patient population. In this study, low adherence was associated with a significantly higher fracture risk compared with high adherence.

This analysis was conducted in a large, comprehensive administrative Medicare claims database that offers a large sample of postmenopausal females for evaluating the association between osteoporosis medication adherence and subsequent fractures. We examined a comprehensive list of osteoporosis medications among Medicare enrollees. In addition, we adjusted for observable confounders that could potentially mediate and/or confound the relationship in our models. Additionally, we used time-dependent cumulative MPR that allowed us to evaluate how changing adherence affected the outcome. 


\section{Examining the Effect of Medication Adherence on Risk of Subsequent Fracture Among Women with a Fragility Fracture in the U.S. Medicare Population}

To date, few studies have explored and addressed the effect of adherence on subsequent fractures among Medicare enrollees. Research in the past has highlighted low persistence and adherence rates among osteoporotic women. A 2007 study (Adachi et al.) showed that only $43 \%$ of patients on bisphosphonates had MPR $\geq 80 \%$ over a 2 -year period. ${ }^{27}$ Another study (Downey et al., 2006) reported 12-month adherence at 60\% among patients with alendronate and risedronate use. $^{28}$ These results are similar to the current study, in which 12-month adherence was 68\%. The study found that half of the patients had high adherence, and the remaining patients had either low or moderate adherence to their osteoporosis therapy. Specifically, 32\% of patients had low adherence, which is consistent with previous research that reported $28 \%-42 \%$ of patients with low adherence. ${ }^{13,29}$ Therefore, a significant proportion of the Medicare study sample had suboptimal adherence to their osteoporosis medications, leading to a reduction in treatment effectiveness and resulting in higher fracture risk.

In this study, low adherence among Medicare patients was associated with a 33\% increased risk of fracture, whereas moderate adherence was associated with a 19\% increased risk of fracture; therefore, as adherence increased, the risk of fracture decreased by as much as 14\% within only 12 months. The study supports previous literature demonstrating that increased adherence has a protective effect on fracture risk. Additionally, the protective effect was observed across fracture types. Patients with low adherence had a 34\% increased risk for clinical vertebral fractures and an approximately 32\% increased risk for hip/pelvis/femur fractures, compared with high adherence. One study (Sampalis et al., 2012) showed that MPR $\geq 80 \%$ resulted in $9.1 \%$ significantly lower odds of fracture risk compared with $\mathrm{MPR}<80 \% .{ }^{30}$

Results from another study (Patrick et al., 2010) showed a similar effect, using cumulative proportion of days covered (PDC), a similar measure to MPR: PDC of $\geq 80 \%$ resulted in a $22 \%$ significantly lower risk of fracture, while a cumulative PDC of 20\%-39\% resulted in a $16 \%$ significantly lower risk of fracture compared with patients with an adherence of 0\%-19\%. ${ }^{31}$ Furthermore, other studies have also demonstrated that MPR has a significant effect on hip, radius, spine, and humerus fractures. Specifically, patients with MPR $<50 \%$ had an $85 \%$ increased risk for a hip fracture and a $67 \%$ increased risk of any major osteoporotic fracture compared with the $\mathrm{MPR} \geq 80 \%{ }^{26}$

Similarly, another study (Burge et al., 2017) showed that a low MPR of teriparatide was associated with 64\% higher likelihood of any fracture, 156\% higher odds of clinical vertebral fracture, and $44 \%$ higher odds of another nonvertebral fracture, when compared with high MPR. ${ }^{24}$ Therefore, our results among Medicare patients are consistent with studies in other populations showing the effect of medication adherence is significant on any subsequent fracture as well as clinical vertebral and hip/pelvis/femur fracture types.

\section{Limitations}

There are several limitations to this study. First, the MPR informed via pharmacy claims assumes that a patient was in possession of the medication during the "days supply period"; however, there is no guaranteed compliance, that is, proof that the medication was actually consumed or taken as prescribed. Second, we did not require at least 2 medication prescription fills; therefore, our population may have included patients who discontinued their medication after the first fill. Third, medications provided as samples by the physician were not observed in the claims data. Also, medications prescribed during hospitalizations were not available in the data, which could have led to underestimating osteoporosis medication use during the study period.

Fourth, our analysis did not distinguish among osteoporosis medication types. The osteoporosis medications examined in this study represent drugs whose efficacy could have influenced the MPR. Fifth, the presence of a diagnosis code in a medical claim is not a confirmation of a disease, as the diagnosis code may be incorrectly coded or included as a rule-out diagnosis. Sixth, we excluded patients who died during the 1-year follow-up; therefore, we do not know if mortality had an effect on fracture risk. Finally, certain information was not readily available in claims data (or could have been randomly missing) that may have influenced study outcomes, such as BMD test results (T-score values), disease-specific parameters, and other laboratory results.

\section{Conclusions}

Medication adherence is a key factor in predicting a subsequent fracture in elderly women with a previous fragility fracture. After adjusting for several relevant covariates, our analyses of Medicare-enrolled women showed significantly higher risk for low and moderate adherent patients for any fracture, while those with low adherence had significantly higher risk of hip/pelvis/femur and clinical vertebral fractures within 12 months. An increasing trend toward subsequent fracture risk from suboptimal adherence for other nonvertebral fractures was also found. An integrated coordination of the care model system should incorporate medication adherence for osteoporosis patients so that orthopedists, pharmacists, and hospital administrators can collectively address near-term challenges and outcomes related to nonadherence and suggest tools to improve the adherence of osteoporosis patients. 


\section{Examining the Effect of Medication Adherence on Risk of Subsequent Fracture Among Women with a Fragility Fracture in the U.S. Medicare Population}

\section{Authors}

ALLISON KESHISHIAN, MPH, and LIN XIE, MA, MS,

STATinMED Research, Ann Arbor, Michigan. NATALIE BOYTSOV,

PhD; KELLY KROHN, MD; LOUISE LOMBARD, MA; and XIANG ZHANG, PhD, Eli Lilly, Indianapolis, Indiana. RUSSEL BURGE, PhD, Eli Lilly, Indianapolis, Indiana, and Winkle College of Pharmacy, University of Cincinnati, Cincinnati, Ohio. ONUR BASER, MS, PhD, Center for Innovation and Outcomes Research, Department of Surgery, Columbia University, and STATinMED Research, New York, New York.

AUTHOR CORRESPONDENCE: Allison Keshishian, MPH, Project Manager, STATinMED Research, 211 N. 4th Ave., Ste. 2B, Ann Arbor, MI 48104. Tel.: 734.222.5426, ext. 323;

E-mail:akeshishian@statinmed.com.

\section{DISCLOSURES}

This study was funded by Eli Lilly. Xie, Keshishian, and Baser are employees of STATinMED Research, a paid consultant to Eli Lilly in connection with the study design, data analysis, and development of the manuscript for this study. Boytsov, Burge, Lombard, and Zhang are employees and stock owners of Eli Lilly. At the time of research, Krohn was an employee of Eli Lilly.

Study concept and design were contributed by Burge and Lombard, along with the other authors. Xie, Baser, and Keshishian took the lead in data collection, assisted by the other authors. Data interpretation was performed by Krohn and Zhang, with assistance from the other authors. The manuscript was written by Keshishian and Boytsov, along with the other authors, and revised by Boytsov, Keshishian, and Burge, along with the other authors.

\section{ACKNOWLEDGMENTS}

Editing assistance was provided by Michael Moriarty of STATinMED Research.

\section{REFERENCES}

1. Endo Y, Aharonoff GB, Zuckerman JD, Egol KA, Koval KJ. Gender differences in patients with hip fracture: a greater risk of morbidity and mortality in men. J Orthop Trauma. 2005;19(1):29-35

2. Kanis JA, Oden A, Johnell O, De Laet C, Jonsson B. Excess mortality after hospitalisation for vertebral fracture. Osteoporos Int. 2004;15(2):108-12.

3. Center JR, Nguyen TV, Schneider D, Sambrook PN, Eisman JA. Mortality after all major types of osteoporotic fracture in men and women: an observational study. Lancet. 1999;353(9156):878-82.

4. Eichner SF, Lloyd KB, Timpe EM. Comparing therapies for postmenopausal osteoporosis prevention and treatment. Ann Pharmacother. 2003;37(5):711-24

5. Siris ES, Selby PL, Saag KG, Borgström F, Herings RM, Silverman SL. Impact of osteoporosis treatment adherence on fracture rates in North America and Europe. Am J Med. 2009;122(2 Suppl):S3-13.

6. Rabenda V, Hiligsmann M, Reginster JY. Poor adherence to oral bisphosphonate treatment and its consequences: a review of the evidence. Expert Opin Pharmacother. 2009;10(14):2303-15.

7. Imaz I, Zegarra P, González-Enríquez J, Rubio B, Alcazar R, Amate JM. Poor bisphosphonate adherence for treatment of osteoporosis increases fracture risk: systematic review and meta-analysis. Osteoporos Int. 2010;21(11):1943-51.
8. Wilkes MM, Navickis RJ, Chan WW, Lewiecki EM. Bisphosphonates and osteoporotic fractures: a cross-design synthesis of results among compliant/ persistent postmenopausal women in clinical practice versus randomized controlled trials. Osteoporos Int. 2010;21(4):679-88.

9. Papaioannou A, Kennedy CC, Dolovich L, Lau E, Adachi JD. Patient adherence to osteoporosis medications: problems, consequences and management strategies. Drugs Aging. 2007;24(1):37-55.

10. McHorney CA, Schousboe JT, Cline RR, Weiss TW. The impact of osteoporosis medication beliefs and side-effect experiences on non-adherence to oral bisphosphonates. Curr Med Res Opin. 2007;23(12):3137-52.

11. Huas D, Debiais F, Blotman F, et al. Compliance and treatment satisfaction of post menopausal women treated for osteoporosis. Compliance with osteoporosis treatment. BMC Womens Health. 2010;10:26.

12. Osterberg L, Blaschke T. Adherence to medication. N Engl J Med. 2005;353(5):487-97.

13. Halpern R, Becker L, Iqbal SU, Kazis LE, Macarios D, Badamgarav E. The association of adherence to osteoporosis therapies with fracture, allcause medical costs, and all-cause hospitalizations: a retrospective claims analysis of female health plan enrollees with osteoporosis. J Manag Care Pharm. 2011;17(1):25-39. Available at: http://www.jmcp.org/doi/10.18553/ jmcp.2011.17.1.25.

14. Wade SW, Satram-Hoang S, Nadkar A, Macarios D, Tosteson AN. Impact of medication adherence on health care utilization and productivity: selfreported data from a cohort of postmenopausal women on osteoporosis therapy. Clin Ther. 2011;33(12):2006-15.

15. 104th Congress, U.S. Department of Health and Human Services. Public Law 104-191: Health Insurance Portability and Accountability Act of 1996. August 21, 1996. Available at: https://www.gpo.gov/fdsys/pkg/PLAW104publ191/pdf/PLAW-104publ191.pdf. Accessed July 19, 2017.

16. Boytsov N, Yu M, Sugihara T, Swindle R. Defining the teriparatide patient: osteoporosis sequence of care and healthcare resources. Am J Pharm Benefits. 2015;7(1):16-23.

17. Leslie WD, Metge CJ, Azimaee M, et al. Direct costs of fractures in Canada and trends 1996-2006: a population-based cost-of-illness analysis. J Bone Miner Res. 2011;26(10):2419-29.

18. Charlson ME, Charlson RE, Peterson JC, Marinopoulos SS, Briggs WM, Hollenberg JP. The Charlson comorbidity index is adapted to predict costs of chronic disease in primary care patients. J Clin Epidemiol. 2008;61(12):1234-40.

19. Von Korff M, Wagner EH, Saunders K. A chronic disease score from automated pharmacy data. J Clin Epidemiol. 1992;45(2):197-203.

20. Therapeutic Research Center. Potentially harmful drugs in the elderly: Beers list. PL Detail-Document \#280610. June 2012. Available at: https:// www.ngna.org/_resources/documentation/chapter/carolina_mountain/ Beers\%20Criteria\%20Literature.pdf. Accessed July 19, 2017.

21. Huybrechts KF, Ishak KJ, Caro JJ. Assessment of compliance with osteoporosis treatment and its consequences in a managed care population Bone. 2006;38(6):922-28.

22. Andrade SE, Kahler KH, Frech F, Chan KA. Methods for evaluation of medication adherence and persistence using automated databases. Pharmacoepidemiol Drug Saf. 2006;15(8):565-74.

23. Siris ES, Harris ST, Rosen CJ, et al. Adherence to bisphosphonate therapy and fracture rates in osteoporotic women: relationship to vertebral and nonvertebral fractures from 2 U.S. claims databases. Mayo Clin Proc. 2006;81(8):1013-22.

24. Burge RT, Disch DP, Gelwicks S, Zhang X, Krege JH. Hip and other fragility fracture incidence in real-world teriparatide-treated patients in the United States. Osteoporos Int. 2017;28(3):799-809.

25. Curtis JR, Yun H, Lange JL, et al. Does medication adherence itself confer fracture protection? An investigation of the healthy adherer effect in observational data. Arthritis Care Res (Hoboken). 2012;64(12):1855-63. 
26. Patrick AR, Shrank WH, Glynn RJ, et al. The association between statin use and outcomes potentially attributable to an unhealthy lifestyle in older adults. Value Health. 2011;14(4):513-20.

27. Adachi J, Lynch N, Middelhoven H, Hunjan M, Cowell W. The association between compliance and persistence with bisphosphonate therapy and fracture risk: a review. BMC Musculoskelet Disord. 2007;8:97.

28. Downey TW, Foltz SH, Boccuzzi SJ, Omar MA, Kahler KH. Adherence and persistence associated with the pharmacologic treatment of osteoporosis in a managed care setting. South Med J. 2006;99(6):570-75.
29. Yu S, Burge RT, Foster SA, Gelwicks S, Meadows ES. The impact of teriparatide adherence and persistence on fracture outcomes. Osteoporos Int. 2012;23(3):1103-13

30. Sampalis JS, Adachi JD, Rampakakis E, Vaillancourt J, Karellis A, Kindundu C. Long-term impact of adherence to oral bisphosphonates on osteoporotic fracture incidence. J Bone Miner Res. 2012;27(1):202-10.

31. Patrick AR, Brookhart MA, Losina E, et al. The complex relation between bisphosphonate adherence and fracture reduction. J Clin Endocrinol Metab. 2010;95(7):3251-59. 


\section{Examining the Effect of Medication Adherence on Risk of Subsequent Fracture Among Women with a Fragility Fracture in the U.S. Medicare Population}

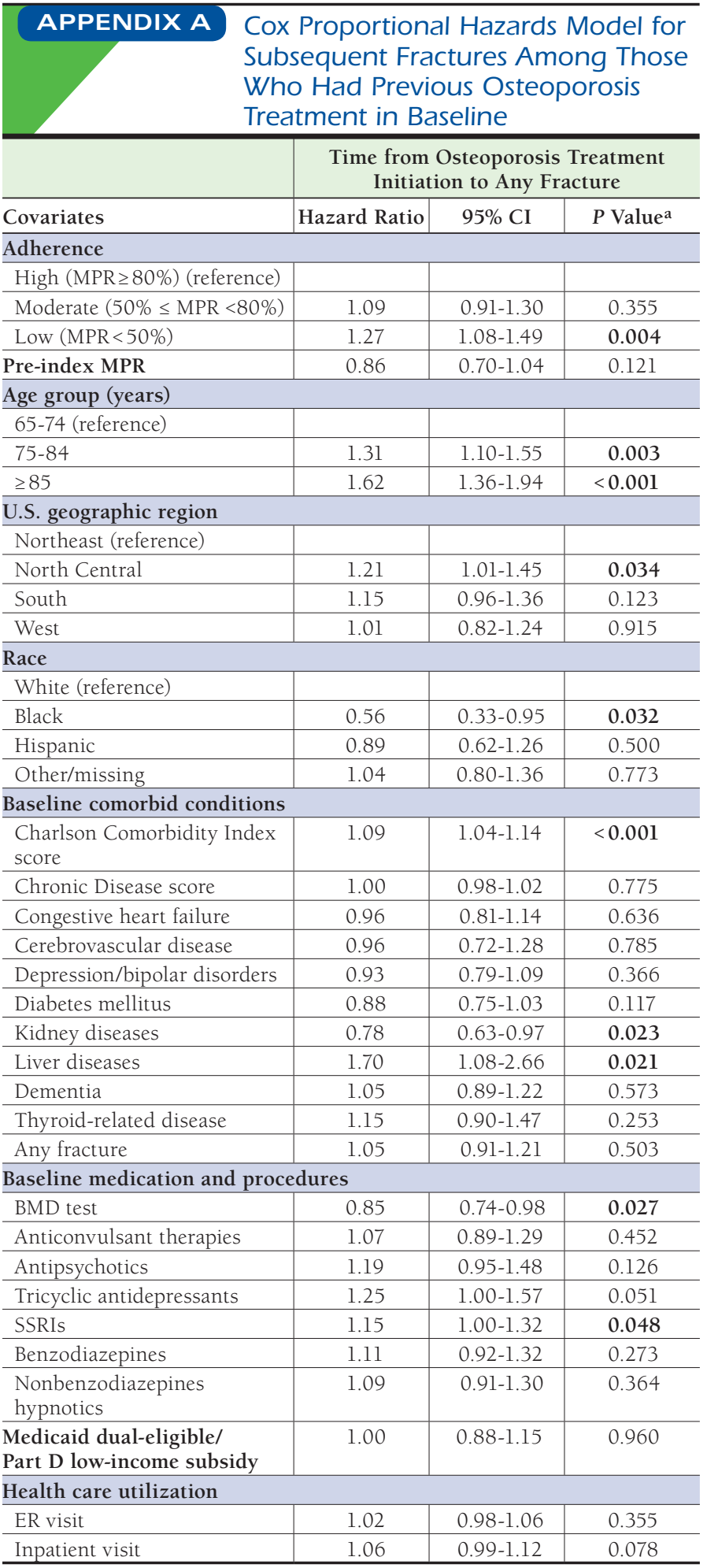

aBold $P$ values indicate significance at $P<0.05$.

$B M D=$ bone mineral density; $C I=$ confidence interval; $E R=$ emergency room; $M P R=$ medication possession ratio; SSRI = selective serotonin reuptake inhibitor

\begin{tabular}{|c|c|c|c|c|c|}
\hline \multirow{3}{*}{$\begin{array}{l}\text { Falsification } \\
\text { Outcomes }\end{array}$} & \multicolumn{5}{|c|}{$\begin{array}{l}\text { Cox Proportional Hazards Model } \\
\text { for Risk of Falsification Outcomes } \\
\text { and Medication Adherence of } \\
\text { Osteoporosis Medications }\end{array}$} \\
\hline & \multicolumn{2}{|c|}{$\begin{array}{l}\text { Low vs. High } \\
\text { Adherence }\end{array}$} & \multicolumn{2}{|c|}{$\begin{array}{l}\text { Moderate vs. High } \\
\text { Adherence }\end{array}$} & \multirow{2}{*}{$\begin{array}{c}P \\
\text { Value }^{\mathrm{a}}\end{array}$} \\
\hline & HR & $95 \%$ CI & HR & $95 \%$ CI & \\
\hline Pneumonia & 1.25 & $0.97-1.60$ & 1.23 & $0.92-1.64$ & 0.062 \\
\hline Septicemia & 1.29 & $0.95-1.75$ & 1.38 & $0.98-1.95$ & 0.064 \\
\hline $\begin{array}{l}\text { Chronic obstructive } \\
\text { bronchitis }\end{array}$ & 1.42 & $1.05-1.92$ & 1.42 & $0.99-2.02$ & 0.017 \\
\hline $\begin{array}{l}\text { Urinary tract } \\
\text { infection }\end{array}$ & 1.24 & $0.98-1.56$ & 1.03 & $0.78-1.37$ & 0.083 \\
\hline Atrial fibrillation & 1.46 & $1.02-2.08$ & 1.42 & $0.94-2.16$ & 0.027 \\
\hline $\begin{array}{l}\text { Coronary } \\
\text { atherosclerosis }\end{array}$ & 2.01 & $1.15-3.51$ & 0.82 & $0.34-2.01$ & 0.019 \\
\hline
\end{tabular}

a Bonferroni adjustments were made for multiplicity control on the comparisons. The Bonferroni significance levels of 0.0084(0.05/6) were used. Hypothesis test: whether at least 1 MPR group is significantly different in risk of falsification outcome.

$C I=$ confidence interval; $H R=$ hazard ratio. 